\title{
HISTORIA DE LA ENFERMERÍA DE SALUD PÚBLICA EN ESPAÑA
}

\author{
JAVIER GÓMEZ ROBLES \\ Manoli Domingo Pozo \\ Seminario de Historia y Antropología de los Cuidados \\ Departamento de Enfermería. Universidad de Alicante
}

\section{RESUMEN}

Actualmente, no existe en España una especialidad de Enfermería de Salud Pública, aunque en 1987 se contemplara su creación según R.D. 992/1987.

Esta situación, sin embargo, era distinta a principios de siglo, cuando aparecía una incipiente figura llamada Visitadora Sanitaria, como enfermera con distinta formación a las que trabajaban en los hospitales o los practicantes, y con una visión comunitaria de los problemas de salud.

Entonces ¿por qué esa figura no ha evolucionado hasta nuestros días convirtiéndose en la enfermera especialista en Salud Comunitaria?

El objetivo de nuestro trabajo es proporcionar una visión global de la historia de la Enfermería de Salud Pública, desde sus inicios en Gran Bretaña y U.S.A., centrándonos posteriormente en la evolución de esta importante figura en España.

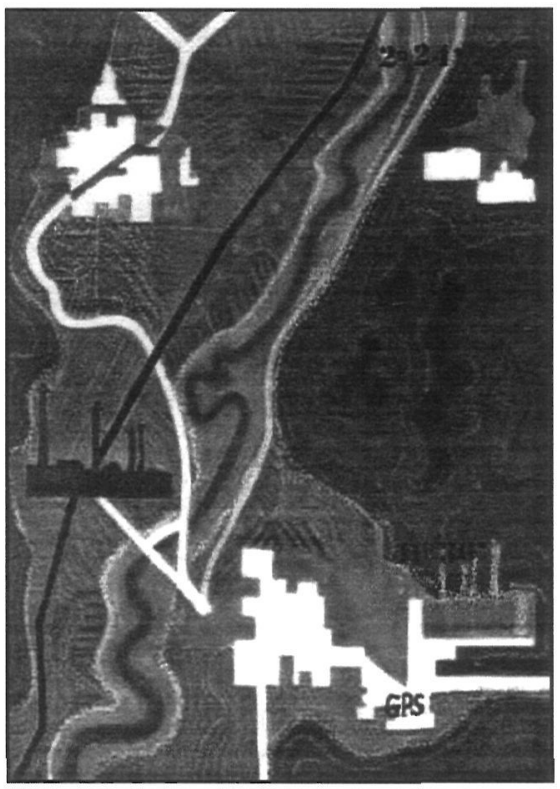

\section{THE PUBLIC HEALTH NURSE HISTORY IN SPAIN}

\section{SUMMARY}

In Spain, at present does not exist the figure of the Public Health Nurse Specialist, although the creation of such a career speciality was taken into consideration by Law in 1987 (R.D: 992/1987).

Nevertheless, the situation was somehow different in the first years of our century when the so called "Visitadora Sanitaria" (similar to District Nurse) was a nurse with a different education to those engaged in hospital clinical work or "practicantes", and who regarded health problems from a wider perspective: with a community vision.

Why has such a figure not evolved into a Community Nursing Specialist?. Our primary aim here is to provide a global vision of Public Health Nursing starting from its origins in Great Britain and in the U.S.A. and focusing later on the evolution of this important figure in Spain. 


\section{LOS ORÍGENES DE LA ENFERMERÍA DE SALUD PÚBLICA}

La Enfemería de Salud Pública nació en el movimiento sanitario inglés del siglo XIX.

Gran número de profesionales sanitarios mostró gran interés por la necesidad de actuación en el ámbito de la comunidad después del " Informe sobre las condiciones sanitarias de la población trabajadora de Gran Bretaña" de Edwin Chadwick (1837)

Hubo 2 intentos por realizar actividades para preservar la salud.

El primer intento fue fallido y lo llevo a cabo la Sociedad Epidemiológica de Londres durante 1854 y 1856. Ellos pensaban que el modelo de asistencia sanitaria fallaba debido a que los médicos eran de una clase social superior a la población a la que atendían. Creían que si formaban a mujeres procedentes de clase trabajadora, la relación que se establecería con la comunidad sería más adecuada para lograr sus objetivos de prevención y promoción de la salud.

El segundo intento, tres años más tarde fue en Liverpool, gracias al mecenazgo de un comerciante llamado William Rathbone.

Las primeras enfermeras de salud pública dividieron la ciudad de Liverpool en 18 distritos y cada una de ellas cubría uno.

Las funciones de estas enfermeras que definió Rathbone eran:

- La visita domiciliaria a enfermos: cambiando así la tradición de la enfermera que no sólo trabajarían en el hospital sino también en la comunidad.

- Educación sanitaria: con especial importancia de las actividades preventivas.

- Asistencia sanitaria.

Estas funciones reflejan el concepto holísta que del hombre y su salud tenía William Rathbone.

Rathbone para asesorarse bien intercambiaba ideas a través de cartas con F. Nigthingale.
Llegaron a la conclusión de la necesidad de un plan de formación para estas enfermeras separadas de las enfermeras de hospital.

En 1862 se abrió la primera escuela de Enfermería de Salud Pública del mundo. El éxito de esta escuela creada por Rathbone hizo que otras instituciones de ciudades inglesas copiaran su modelo. Así nacieron más escuelas en Manchester (1864), Leicester (1867), Londres (1868), Birminghan (1870) y Glasgow (1875).

En los E.E.U.U., aunque la situación económica que allí tenían era totalmente diferente a la inglesa, se produce durante el siglo XIX un proceso similar al movimiento sanitarista inglés.

A. Lemuel Shattuck en su informe (repercusión parecida a la del informe Chadwick en Inglaterra), dio consejos al gobierno sobre la necesidad de formación de profesionales de la enfermería.

\section{LOS ORÍGENES DE LA ENFERMERÍA Y LA SALUD PÚBLICA EN ESPAÑA}

Durante todo el siglo XVIII y hasta finales del XIX los profesionales de la enfermería ejercían 3 funciones: callistas, dentistas y asistentes a partos.

El arte del dentista que figuró en los planes de estudios hasta 1888 fue sustraido en 1877 mediante Real Decreto.

Sin embargo las ideas anglosajonas de enfermería para la salud no tuvieron mucho eco en las enfermeras españolas. Las razones que pueden explicar esta falta de tradición:

- No existió en España un movimiento parecido al inglés

- En España existían en el siglo XIX una riquísima tradición de la enfermería hospitalaria.

Hasta 1857, con la Ley de Instrucción Pública aparece en España la primera legislación sobre los conocimientos de las aspirantes a practicantes. 
La primera escuela se denominó " Cuerpo de Enfermeras de Santa Isabel de Hungría". Su esquema de formación era biologicista y técnica.

La promulgación de la Instrucción General de Sanidad de 1904 permitió diseñar las directrices en materia de políticas sanitarias.

En 1915 se aprueba el primer plan de estudios de carácter nacional y hasta 1936, la legislación va avanzando para dotar al país de una estructura organizativa que resolviera los problemas de salud de los españoles.

Una de las principales limitaciones era la falta de profesionales para desarrollar y aplicar las cuestiones y materias relacionadas con la higiene y sanidad pública.

A lo largo de los años 20 y 30 tuvo lugar la creación y dotación de diferentes instituciones docentes como la Escuela Nacional de Puericultua (1923), la Escuela Nacional de Sanidad (1925), o la Escuela Nacional de Enfermeras Visitadoras (1932).

Este proceso de institucionalización de la visitadora sanitaria no puede separarse de la propia evolución de la enfermería en la España de finales de siglo XIX y primeras décadas del XX.

\section{LOS ANTECEDENTES DE LA VISITADORA SANITARIA}

En 1923 se creaba la Escuela Nacional de Puericultura, para proporcionar asistencia a la población infantil, con miras a reducir la mortalidad de este grupo de edad y mejorar su estado de salud. Fue proyectado para ser un centro eminentemente docente y científico, y el dato más significativo era su carácter multidisciplinario. Los títulos que se expedían en esta escuela eran: Médicos Puericultores, Matronas Puericultoras, Visitadoras Puericultoras, Maestros Puericultores y Guardadoras de niños (niñeras tituladas). Con esto se intentaba abarcar la totalidad del ambiente que rodea al niño.

El primer curso tuvo lugar en Octubre de 1926. Las Visitadoras Puericultoras tenía que hacer dos cursillos de 5 meses de duración cada uno. Al finalizar el curso realizaban unas pruebas para obtener el título.

Las aspirantes que no tenían el bachillerato o el Titulo de Maestra y quisieran hacer los estudios de Visitadora Puericultora tenían que realizar una prueba de ingreso ante los profesores de la Escuela.

La Escuela Nacional de Puericultura podía establecer sucursales en las provincias, y concedía el carácter de Escuela Provincial a los centros que lo solicitaban, previa aprobación del programa.

Las disciplinas que se impartían eran: Eugenesia y Puericultura intrauterina, Fisiología e Higiene infantil, Puericultura de la primera y segunda infancia, Legislación y obras internacionales proinfancia y Laboratorio aplicado a la Puericultura. Las prácticas eran ejercicios referentes a la preparación para la labor asisitencial, social y colaboración sanitaria.

Las diferentes ubicaciones de los profesionales que salían de la Escuela Nacional de Puericultura estaban garantizadas, ya que tenían preferencia sobre otros.

También se crearon numerosos centros donde estos titulados ejercían su trabajo, como los Dispensarios Móviles Infantiles, los Servicios Provinciales de Higiene Infantil, etc., y cuyas funciones eran dar consejo y vigilar el estado de salud de madres e hijos.

\section{A. LA ESCUELA NACIONAL DE SANIDAD Y LA ESCUELA DE ENFERMERAS VISITADORAS SANITARIAS}

En el proceso de formación de las Enfermeras Visitadoras destaca el papel de Concepción Arenal, como su precursora en la España de 1935. Existía una gran similtud entre el planteamiento de la idea de Visitadora defendida por Arenal y las actividades que llegaron a realizar las Enfermeras Visitadoras de los años 30

En la obra "El visitador del pobre" de 1860 se puede apreciar la faceta comunitaria que caracterizaba a las Enfermeras Visitadoras. 
El objetivo de formar en España un cuerpo de Enfermeras Visitadoras aparece unido a la creación de la primera Escuela de Salud Pública en nuestro país y la Escuela Nacional de Sanidad. Las primeras actividades docentes en la formación de Visitadoras comienza en Febrero de 1933. Se crean las primeras 50 plazas que llevarían a cabo su trabajo en los Dispensarios Antituberculosos de Madrid y provincias, en los Centros de Higiene rural y los de Puericultura.

La Escuela Nacional de Sanidad anuncia su colaboración con la Fundación Rockefeller en 1931. La Fundación se comprometía a sufragar los costes en la construcción de la futura Escuela de Visitadoras y a dar becas para una formación de postgrado en Enfermería de Salud Pública a las futuras docentes de esta escuela. Así, como paso previo, la Fundación Rockefeller realizó en 1931 un análisis de la situación de la Enfermería en España. De este análisis se encargó Elisabeth Crowell. En su informe, Crowell puso de manifiesto que la enseñanza teórica era desorganizada y descoordinada, impartida por médicos y no por Enfermeras. En su opinión la profesionalidad de las Enfermeras españolas era muy deficiente. También analizó las actividades de la Enfermería de Salud Pública, destacando tres experiencias: las iniciativas de Cruz Roja de Madrid, la Escuela Nacional de Puericultura y el Instituto Provincial de Higiene de Cáceres.

Entre 1931 y 1936 se desplazaron a Estados Unidos un total de 14 Enfermeras. La duración media de la estancia fue de 2 años, aunque la beca inicial era de un año. Pero la deficiente formación, así como el idioma, fueron las causas de esta ampliación.

El programa de estudios consisitía en la participación como estudiantes en la Escuela de Enfermería en la Western University of Cliveland. Allí seguían enseñanzas como: Enfermería fundamental, Avances en Enfermería, Principios y métodos de la enseñanza en Enfermería, aspectos sociales y Salud Pública.

Estos conocimientos se completaban con una estancia de varios meses en East Harlem Nursing and Healt Service de Nueva York.
Todo este esfuerzo no sirvió para alcanzar el objetivo planteado, que era la incorporación de estas profesionales a la Escuela Nacional de Enfermeras Visitadoras de Madrid, debido, entre otras causas, a la Guerra Civil de 1936.

El primer curso de Enfermeras Visitadoras, que comenzó en Febrero de 1933, como anteriormente se ha señalado, tenía una duración de 3 meses, con una parte teórica y otra práctica. Las enseñanzas impartidas se dividían en las siguientes temáticas:

-Higiene general.

-Higiene del trabajo.

-Higiene escolar.

-Higiene de la alimentación.

-Estadística sanitaria y Demografía.

-Medicina Social.

-Fichas epidemiológicas.

-Propaganda.

-Ficha y hoja clínica.

-Ficheros y archivos.

-Administración y legislación sanitaria.

Las prácticas se desarrollaban en los Centros Secundarios de Higiene Rural de Sigüenza y Valdepeñas, y en los Institutos de Navalmoral de la Mata y Cáceres.

En los primeros cursos había un requisito de ingreso en la Escuela, la posesión del Título de Practicante, Enfermera o Matrona.

En Febrero de 1934, se crea una Comisión Gestora para que trabajase en la organización de la futura Escuela de Enfermeras Visitadoras. Tanto el modelo de escuela como el carácter de la formación de las Enfermeras fue objeto de debate. Así, Antonio del Campo, Inspector Provincial de Sanidad de Cáceres, era partidario de la formación generalista de las Visitadoras frente a la Formación especializada. En su misma línea se encontraba el Director Provincial de Sanidad de Albacete, el Dr. J. Pérez Mel. El modelo de organización de Pérez Mel defiende es el internado y entre los requisitos de admisión las aspirantes debían tener el Título de Bachiller o Maestra.

La duración de los estudios era de tres años:

1. Primer curso:

-Contenidos preliminares: Anatomía y Fisiolo- 
gía, Química, Farmacología, Patología general, Higiene individual, Ética de la Enfermera e Historia de la profesión, Educación física.

-Resto de contenidos teóricos: Patología Médica, Patología Quirúrgica, Otorrinolaringología, Neurología y Psiquiatría, Higiene general.

-Actividad práctica: 3 meses en servicios de Patología interna y quirúrgica, 2 semanas en administración sanitaria y prácticas de preparación de regímenes dietéticos.

\section{Segundo curso:}

-Contenidos teóricos: Obstetricia y Ginecología, desarrollo del niño sano y Pediatría, Enfermedades Infecciosas, Bacteriología, Dermatología, Venerología y Oftalmología.

-Actividad práctica: 2 meses en un servicio de Obstetricia, 2 en uno de Pediatría, 3 en el Hospital de Infecciosas, 1 en un Preventorio y otro en un Sanatorio Antituberculoso.

\section{Tercer curso:}

- Contenidos teóricos: Medicina Social, Epidemiología, Organización y administración sanitaria, Psicología y Pedagogía.

- Actividad práctica: estancia durante todo el curso en un Centro de Higiene, pasando por los distintos servicios de Higiene Social.

En lo referente al profesorado, Pérez Mel creía que las enseñanzas teóricas debían estar a cargo de los médicos, y las prácticas, por Enfermeras capacitadas.

En Enero de 1935 se nombró la comisión encargada de redactar el reglamento interno de la Escuela de Enfermeras Sanitarias. Para poder ingresar en la nueva Escuela no se necesitaba el Título de Enfermera, sino haber acabado el Bachiller o Magisterio, o en su defecto, superar un exámen.

Antonio del Campo hablaba de las "cualidades mínimas de las Enfermeras Visitadoras y los objetivos de su trabajo". Él recoge la propuesta de la Organización Norteamericana de las Enfermeras Visitadoras (nophn)." Los objetivos a conseguir en el trabajo pueden dividirse en generales y especiales para cada servicio. Los generales son:
Educación sanitaria al individuo y su familia, ayuda en el ajuste de las condiciones sociales y familiares que pueden afectar la salud de la familia, relacionar los programas sociales y sanitarios que influyen en el bienestar de la comunidad, y por último, propagar entre la gente la necesidad que se facilite la labor sanitaria. Entre los objetivos especiales: Maternología, Infantil, Preescolar, Escolar, Adultos, Morbilidad, Enfermedades Infecciosa, Tuberculosis, Venéreas, Mental, Ortopedia e Industrial ".

\section{B. LA ASOCIACIÓN PROFESIONAL DE VISITADORAS SANITARIAS.}

En Marzo de 1934 se crea la Asociación Profesional de Visitadoras Sanitarias, presidida por Mercedes Milá. Los fines de la Asociación eran: fomento de las actividades para mejorar la Salud Pública, mejora en la formación de las Enfermeras y conseguir apoyos para el progreso de la profesión.

Pusieron en marcha una publicación, " La Visitadora Sanitaria. Boletín de la Asociación Profesional de Visitadoras Sanitarias ", con una periodicidad trimestral. El último número fue el 5, en el último trimestre de 1935. El análisis de las publicaciones permite conocer las actividades que desempeñaban, desde estudiar las condiciones sociales y sanitarias de los individuos y familias, conocer el estado de las viviendas, los hábitos y características de su alimentación, hasta explicar a la población la forma de obtener provecho higiénico de sus condiciones de vida, incluso llegando a plantearse la posible modificación de circunstancias perjudiciales para la salud.

\section{LA ENFERMERÍA DE SALUD PÚBLICA DESDE LA GUERRA CIVIL HASTA LA APARICIÓN DEL A.T.S.}

Tras el paréntesis que supone la Guerra Civil española (1936-1939) y la posterior instauración de un nuevo y largo régimen político, se trunca bruscamente el incipiente, aunque importante, grado de 
institucionalización de la Enfermería de Salud Pública.

Durante la Guerra Civil, sobre todo en la parte nacional, la asistencia en los hospitales era prestada por mujeres jovenes sin la formación adecuada para ello. Su entusiasmo y patriotismo era suficiente en esos momentos. Pero una vez acabada la Guerra Civil se tenia que formar a estas mujeres y dotarlas de los conocimientos "para que fuesen más provechosas para la sociedad".

El edificio que habia sido construído en 1936 en Madrid para albergar la Escuela de Enfermeras Sanitarias y de asistencia pública, quedó en un estado lamentable tras la gran guerra, durante la cual sirvió de hospital y más tarde de cuartel republicano. Tras una rápida reconstrucción, se ponía en marcha en 1941 la Escuela Nacional de Instructoras Sanitarias, situada junto al hospital del Rey, a varios kilómetros de Madrid.

Esta escuela tenía una doble función moral y técnica y el objetivo final era "dotar a la Sanidad Nacional de un método auxiliar eficaz, adaptado a los adelantos técnicos". La función educadora encaminada a la formación era similar a la de las Enfermeras Visitadoras. La nueva misión era la de " crear la vocación espiritual necesaria para cumplir su cometido". No sólo debían conocer datos epidemiológicos, estadísticos y censales sino también el estado social de la población, su disciplina y hasta su psicología. La Instructora Sanitaria sería la profesional encargada de cumplir con todas estas funciones, valiéndose de la propaganda y la educación intrafamiliar.

La Escuela Nacional de Instructoras funcionaba en régimen de internado. El ingreso en ella tenía lugar mediante concurso- examen de enfermeras con titulación previa, teniendo en cuenta de forma importante la vocación de la joven que lo solicitaba.

Fisícamente, la escuela era "sencilla, bonita y limpia" y su contenido "disciplinado, estudioso e impregnado de la máxima camaradería, alegre sin frivolidades y obediente por responsabilidad ".

Las actividades en la escuela comenzaban a la 8:00 h. Y acababan a la 22:30 h. Durante este hora- rio se alternaban las clases teóricas y prácticas con las horas de estudio, misas y oraciones.

El director del centro era nombrado por la Dirección General de Sanidad, siendo el primero José Fernández Turégano, y las mujeres que se encargarían de formar a las alumnas pertenecerían a la Delegación Nacional de la Sección Femenina.

Las alumnas para Instructoras Sanitarias polivalentes recibían las siguientes enseñanzas:

- Cultura General: aritmética y gramática, ciencias naturales, geografía, historia y arte.

- Religión : práctica diaria para exhaltar la vocación y patriotismo de las alumnas.

- Nacionalsindicalismo

- Epidemiología y enfermedades infecciosas y exámenes de salud.

- Higiene general

- Tuberculosis (tisiología y enfermedades del tórax).

- Puericultura y maternología.

- Alimentación y prácticas de laboratorio.

- Medicina y cirugía.

- Educación

- Educación física y música.

- Ciencias domésticas.

- Deontología de la profesión.

En cuanto a las clases prácticas iban desde técnicas de laboratorio, vacunaciones, curas e inyectables hasta la elaboración de fichas con datos de las familias.

Tras este año de formación se obtenía el título de Instructora Sanitaria. Después existían dos programas especiales para las instructoras de puericultura y del Patronato Nacional Antituberculoso.

No es hasta 1946 cuando se aprueba el reglamento de la Escuela Central de Instructoras Sanitarias (filial de E.N.S.). Estas instructoras, unas 40 ó 60 en cada promoción, cumplían su función principalmente en las Delegaciones Provinciales de Sanidad. Esta escuela ha seguido funcionando hasta 1983.

Aunque existía un planteamiento de continuidad del proyecto de los años 30 , por lo menos sobre el papel, lo cierto es que nunca se llevó a cabo, y no 
sólo por los cambios puros en la formación (introducción de formación política). Varios hechos acontecidos durante los primeros años del franquismo afectaron seriamente el futuro de la escuela y de las profesionales:

$\S$ Aparición en enero de 1942 de una titulación paralela a la de las Instructoras Sanitarias, creada al margen de la propia escuela y de los organismos oficiales, pero con contenidos similares; esta titulación era la de Cuerpo de Enfermeras de Falange Española Tradicionalista (f.e.t.) y de las J.O.N.S.

\section{$\S$ Aparición también en 1942 del Seguro} Obligatorio de Enfermedad, con la consecuente demanda de profesionales de enfermería.

$\S$ Pluralidad de colectivos profesionales que trabajaban en contenidos propios de la Enfermería de Salud Pública y la diversidad de administraciones donde se insertaban.

$\S$ Falta de profesorado capacitado para impartir todas las enseñanzas previstas en el currículum de la escuela, de modo especial las materias propias de salud pública.

$\S$ Por último, y posteriormente aparición en diciembre de 1953 de la figura del A.T.S., apuesta definitiva por un modelo de enfermería centrado en las tareas asistenciales.

Ante todas estas adversidades contra la figura de la Enfermera de Salud Pública, se sucedían las reivindicaciones de los profesionales. Como ejemplo, citar las reivindicaciones en 1959 dentro de la Asamblea de Enfermeras de la Sanidad Nacional en Madrid, que demandaban un centro capaz de formar adecuadamente Enfermeras sanitarias.

Se ha comentado que un hecho que afectó negativamente al futuro de la enfermería comunitaria fue la creación, al margen de la Escuela de Instructoras Sanitarias, de una nueva titulación, el Cuerpo de Enfermeras de la Falange Española y Tradicionalista y de las JONS, además de la aparición de otro tipo de Enfermeras, las Visitadoras Sociales, en 1942 (ley de 3 de Enero). El objetivo final de estas titulaciones "no oficiales" era regularizar la situación de las mujeres que cargadas de "cualidades de valor, abnegación y sacrificio im- prescindible" habían ejercido las funciones de Enfermera durante la guerra en el bando vencedor, sin la titulación correspondiente. Estas mujeres no podían acceder al título de Instructora Sanitaria, ya que se exigía ser Enfermera titulada o Visitadora Sanitaria. Estas nuevas titulaciones se llevaban totalmente al margen de las instituciones docentes y reflejaban la posibilidad de especializarse en dos campos: Enfermera de Guerra y Enfermera Visitadora Social.

Las Enfermeras Visitadoras Sociales consiguieron el reconocimiento oficial en 1945, y encontraron su campo profesional en la incipiente estructura de Seguro Obligatorio de Enfermedad (SOE). Su función era "control del uso o abuso de las ventajas que el Seguro ofrece a los beneficiarios asegurados". Estas profesionales se beneficiaron de los altos sueldos, muy superiores a los de las Instructoras de Sanidad.

Al caos existente ante la duplicidad entre las Instructoras y la Visitadoras Sociales, se le añadía la existencia de otras profesionales que se ocupaban de contenidos propios de la Enfermería de Salud Pública:

\section{$\S$ Enfermeras del Gran Hospital y Auxilio} Social (dependientes de la Dirección General de Beneficencia), con cometidos en consultas de Puericultura, visitas, hogares, maternidades,...

$\S$ Enfermeras de Higiene Escolar y Divulgadoras Rurales. Estos dos tipos de profesionales basaban sus actividades en la lucha contra la mortalidad infantil y protección del niño. A través de una cuidadosa recogida de datos sobre la historia obstétrica de la madre, datos familiares, datos sobre los niños, sobre las condiciones higiénicas de la vivienda,... podían llegar a conocer las causas de la alta mortalidad infantil y así orientar los esfuerzos en su lucha. También trabajaban en los recién creados dispensarios de maternología, casas maternales, dispensarios de puericultura (denominación que se dió a las antiguas gotas de leche), dispensarios escolares, campamentos de verano, etc. Con el objetivo de aumentar la salud materno-infantil.

Ante tal diversidad de títulos, reconocidos o no, se hacía necesaria una gran reforma de los estudios 
de los profesionales de Enfermería. Así, en 1952 aparece un diseño de un nuevo plan de estudios con orientación claramente progresista, donde se reflejaban asignaturas de marcado carácter comunitario: Sociología, Higiene Mental, Medicina Preventiva, etc.

\section{DE LA VISIÓN TECNICISTA DEL ATS AL RETORNO COMUNITARIO CON EL DUE}

La gran propuesta a favor de la Enfermería Comunitaria se va al traste con la aparición del Real Decreto de 4 de Diciembre de 1953, que unificaba en una sola profesión, Ayudante Técnico Sanitario masculino o femenino, todas las que existían hasta el momento: Practicantes, matronas y toda la gama de enfermeras.

En 1955 se publica íntegramente el plan de estudios de los ATS y se declara la profesión de Enfermera como a extinguir. Según Rico Avelló, director de la Escuela de Instructoras Sanitarias en ese momento, "este plan de estudios otorga escasa atención y mínima inquietud por los problemas y situaciones médico-sociales, al mismo tiempo que aprecio un exceso de materias detalladas de Anatomía, Fisiología, Patología médica, Patología quirúrgica, Terapéutica, etc. "

La formación de los ATS refleja la obligatoriedad del internado de los alumnos y la no coeducación entre los dos sexos.

Esta nueva profesión no suponía un problema excesivo para los profesionales de Enfermería dedicados al área asistencial, todo lo contrario que para los de Salud Pública, ya que con ella desaparecería este importante campo de actuación.

En este momento fueron varias las figuras de Enfermeras Visitadoras que reivindicaron mejoras socio-laborales para las que todavía ejercían, creación de una titulación específica e independiente para las Enfermeras de Salud Pública, cursos de perfeccionamiento y solicitud del cese de todas aquellas religiosas que no hubiesen hecho oposición ni pasado por la Escuela de Instructoras. Como ejemplo de una de estas importantes figuras, destacamos a Clementina Juderías, una de las Enfermeras Visitadoras que más había contribuído al desarrollo de la Asociación de Enfermeras
Visitadoras en 1934.

Desdichadamente ninguna de estas ambiciosas propuestas se llevó a cabo y siguió existiendo exclusivamente la titulación de ATS hasta el año 1977.

En este año, la Enfermería española dio un paso importantísimo, ya que se suprimió el internado, se permitió la enseñanza mixta y, lo más importante, se convirtió en disciplina universitaria, con todo lo que ello conlleva, expidiéndose a partir de ese momento el título de Diplomado Universitario en Enfermería (DUE). Actualmente la formación de los DUE tiene una clara orientación preventiva (se observa, por ejemplo, en el cambio de denominación de las materias, como Salud materno-infantil por Pediatría), y dentro de su currículum aparecen asignaturas como Salud Pública I y II, Promoción y educación para la salud, Enfermería comunitaria, Intervención Comunitaria, etc.

A partir de 1980 se posibilita, durante varios años, la homologación del título de ATS con el de DUE, formando a los primeros en temas de Salud Pública, obviados en su plan de estudios, entre otros.

En el año 1987, según Real Decreto 992/1987 de 3 de Julio, se contempla la creación de una especialidad de Enfermería en Salud Comunitaria, como lo son actualmente las especialidades de Salud Mental y Matrona. Pero, hasta el momento, esa especialidad no se ha llevado a cabo.

Lo ocurrido con la Enfermería de Salud Pública a raiz del paréntesis de la Guerra Civil, del posterior régimen franquista y de la aparición del ATS, nos ayuda a entender la evolución de la Salud Pública en general en nuestro país y explica, concretamente, la desaparición de una especialidad de Enfermería con tanta demanda y tradición.

Paradójicamente, 137 años después de que la Escuela Rathbone empezara a funcionar en gran Bretaña, aún no podemos hablar de una especialidad de Enfermería de Salud Pública en España. 


\section{8 - Cultura de los Cuidados}

A la vista de la revisión histórica, se pueden extraer las siguientes reflexiones:

$\S$ En España, quizás por el gran paréntesis que supuso la Guerra Civil, se interrumpió la institucionalización de la Enfermera visitadora. Después, pasados algunos años, con el plan biologista del Ayudante Técnico Sanitario, se truncó definitivamente el desarrollo de la enfermería de Salud Pública.

$\S$ El título de ATS tuvo gran importancia e influencia en el colectivo de Enfermería, que asumió el término de ATS abandonando el clásico de Enfermera. Aún hoy, 21 años después de que la Enfermería se convirtiese en disciplina universitaria, la sociedad y parte del propio colectivo continúan con la concepción técnica de la profesión, sin avanzar hacia el concepto mucho más amplio del DUE.

§ Si la figura del ATS no hubiese existido, tal vez hoy podríamos hablar de la especialidad de Enfermería de Salud Pública como una realidad, formada por profesionales de gran calidad.

$\S$ Actualmente, si estudiamos el plan de estudios del DUE observamos su orientación en promoción de la salud, a través de múltiples asignaturas relacionadas con la Salud Pública, como son: Salud Pública I y II, Educación para la salud, Enfermería Comunitaria, Intervención Comunitaria,... y asignaturas relacionadas con la Epidemiología como Bioestadística, Evaluación de intervenciones en Enfermería,..., que evidencian el avance hacia una especialidad de Enfermería en Salud Pública.

\section{BIBLIOGRAFÍA}

Álvarez-Dardet, C; Gascón, E; Alfonso, MT; Almero, A. (1988) Los orígenes de la Enfermería de Salud Pública. Gaceta sanitaria n.9, vol.2.

Álvarez Romero, E. (1943) Higiene infantil e instructoras de sanidad. Revista de Sanidad e Higiene Pública.

Bernabeu Mestre, J; Gascón Pérez, E. (1995) El pa- pel de la Enfermería en el desarrollo de la Salud Pública española (1923-1935): la visitadora sanitaria. Dynamis Acta. Hisp. Med. Sci. Hist. Illus. 15, 151-176.

Bernabeu Mestre, J ; Gascón Pérez, E. (1998) De visitadoras a instructoras: la Enfermería de Salud Pública durante el primer franquismo (1941-1955). X Congreso de la Sociedad de Historia de la Medicina. Malaga Febrero 1996.

Bernabeu Mestre, J ; Gascón Pérez, E. (1993) Antecedentes históricos de la visitadora sanitaria: el papel de Concepción Arenal como precursora.II Jornadas Nacionales de investigación en historia de la Enfermería en España 1y 2 octubre 1993, Albacete.

Del Campo, Antonio. (1932) Enfermeras visitadoras generalizadas y especializadas. Boletín Técnico de Sanidad.

Del Campo, Antonio. (1932) Cualidades mínimas de las visitadoras sanitarias. Boletín Técnico de Sanidad.

Escuela Nacional de Sanidad. (1943) Revista de Sanidad e Higiene Pública.

Siles González, J. (1990) Evolución histórica de una profesión multidisciplinaria: la Enfermería y la Salud Pública en la España contemporánea. Alacant Sanitari. N ${ }^{\circ} 7,15-$ 18

Suárez de Puga, L. (1941) Colaboración de las Divulgadoras rurales con la sanidad nacional en el conocimiento y lucha contra la mortalidad infantil. Revista de Sanidad e Higiene Pública.

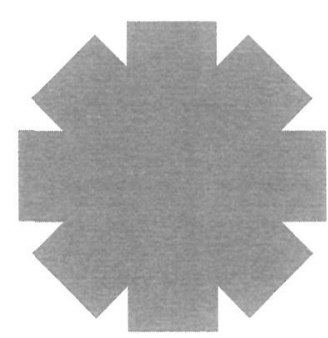

